results are the product of a special clinic devoted to toe conditions and of their enthusiastic application of a detailed and time-consuming regime. They reverted to conservative treatment because of the unsatisfactory results of radical surgery. I maintain, however, that radical surgery, logically and meticulously performed, offers the only certain cure for embedded toenail and onychogryphosis.

The anatomical basis of rational toenail ablation was established in 1887 by Quénu. $\mathrm{He}$ demonstrated that longitudinal nail growth occurred only from the lunular area of the nail bed (germinal matrix). He showed that excision of the germinal matrix would result in permanent ablation of the nail plate.

Since then scores of operations for embedded nails have been devised, most of which failed to apply the principle of a careful dissection of the germinal matrix as an exactly defined anatomical structure. Excision of wedges of nail wall and nail bed, curettage of nail bed, etc., have been advocated in various forms and found wanting. This has resulted in a swing towards the extreme procedure of terminal amputation of the toe, an operation which, ironically enough, does not always prevent sprouts of nail growing through the suture line. Yet from time to time Quénu's principle has been rediscovered and has been described by Wilson, ${ }^{2}$ Heifetz, ${ }^{3}$ and Zadik."

In 1958 I reported the results of 100 toenail ablations using Quénu's principle. ${ }^{5}$ In the 50 cases of embedded toenails there were no recurrences of symptoms in a follow-up of six months to five years. This compares with the figures quoted by Lloyd-Davies and Brill, who report that after two years only $50 \%$ of their cases had been cured.

Moreover, they had $40 \%$ of defaulters, of whom 16 could not be traced. This defaulter rate underlines the problem of conservative treatment of this condition. About $75 \%$ of patients with embedded toenails are active youngsters with sweaty feet. They are not the type of person who can be easily persuaded to attend a toe clinic for a long period of treatment and follow-up. It is far more satisfactory for all concerned to offer the patient a simple out-patient operation under local anaesthesia which results in permanent cure after 10 days.

Lloyd-Davies ${ }^{6}$ has condemned excision of the germinal matrix because he found recurrences after this operation. I find this difficult to explain, but I can only say that with the operative technique I have described recurrences do not occur. I am of the opinion, however, that most of the bad results of ablative nail surgery are due to the failure to apply delicate and exact dissection techniques to a precisely defined anatomical structure. The frequent use of the term "avulsion of the nail" and the frequent suggestion in the literature of toenail surgery that the nail bed should be "curetted" are evidences of a crude approach to the problem which goes a long way to

explain why toenail surgery remains in the doldrums. - I am, etc.,
Bridgend General Hospital,
A. W. FoWLer.
Bridgend, Glamorgan.

REFERENCES

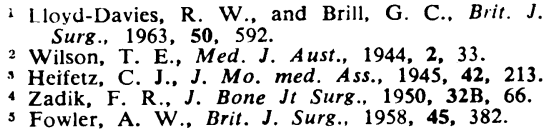

Zadik, F. R., J. Bone Jt Surg., 1950, 32B, 66.

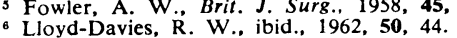

\title{
Spontaneous Regression of Cancer
}

SIR.-Dr. Isobel P. Beswick and $\mathrm{Mr}$. G. Qvist (October 12, p. 930) record a remarkable case of unexpected survival after treatment for generalized cancer, not to be confused with spontaneous regression. Another way of looking at it would be as an illustration of the sensitivity of presumed microscopic deposits

\section{POINTS FROM LETTERS}

\section{Bath-tubs and Hygiene}

Professor N. IsLaM (London N.W.1) writes: Bath-tubs must have a long, long history. This is no reason why they should be so zealously preserved. It is at times horrifying to see six to eight persons using the same bath-tub one after another with a little rinsing with soap and water in between. I am afraid I cannot call it hygienic in any way. And in what way are they supcrior to showers? Is it because of tradition that this unhygienic habit is still in practice in a country which has contributed much in the field of preventive medicine?

History of Hospitals

Mr. J. P. ENTRaCt (The London Hospital Medical College Library, London E.1) writes: Your reviewer of St. John's Hospital for Diseases of the Skin, 1863-1963 states (August 31, p. 556) that the example (of hospital history writing) was set by Sir Norman Moore in 1918, when he published his History of St. Bartholomew's Hospital. This is incorrect. In $1910 \mathrm{~A}$ History of the London Hospital by E. W. Morris was published, while as far back as 1892 a Biographical History of Guy's Hospital was produced by Sir S. Wilks and G. T. Bettany.

\section{Deans of Employment ?}

Dr. RudolPH PaYNe (Norwich) writes: Reading your Educational Number of September 7 it occurred to me that at the present time the National Health Service is missing the equivalent of the father-figure of the old-fashioned "Honorary" who had contacts in his own specialty all over the world, wielded influence in the local hospitals, and was consulted regarding their practice staffing problems by the general practitioners. I cannot help feeling that everybody would benefit if each area would have a "Dean of Employment" who would co-ordinate the demands of the regional board, executive councils, local authorities, etc., with the needs of the young doctors who are nowadays lost in the maze of regulations, directives, and advertisements of the various bodies.

\section{Abortion Law Reform}

Dr. J. FanNING (London S.W.19) writes: With reference to Dr. Evelyn Fisher's letter (September 21, p. 751) I should like to point of undifferentiated carcinoma to radiation. Frequently a "combined treatment" policy may be successful where surgery or radiotherapy alone may fail.

I do not see how this case demonstrates the advantage to the patient of being left in complete ignorance of his diseáse. First, we do not know if he was completely ignorant just because he asked no questions. Many patients are well aware of the probable significance of their disease and simply do not wish to discuss it. Secondly, he might have behaved with the same "absolute faith" even if he had been told the truth. Besides, there are ways of garnishing the most unpleasant truth to make it palatable without removing hope. To me, the last paragraph of the letter displays well the muddled thinking that bedevils cancer therapy at present.--I am, etc.,

Radiotherapy Department, JOHN M. BRINDLE.

Camborne-Redruth Hosnital.

Redruth, Cornwall.

out that it is laid down in Canon Law in the Roman Catholic Church that every aborted foetus is to be baptized if it is alive. If there is doubt as to whether it is alive it should be baptized conditionally. If necessary, of course, any lay person may carry out the baptism.

\section{Wheeled Lavatory Chair}

Dr. Katharine Buchenaigh (Sherborne) writes: A wheeled lavatory chair (September 21, p 751) is in common use in hospitals both general and geriatric. The usual skeleton aluminium chair has four wheels and can, of course, be pushed. It has an ordinary lavatory type seat, usually plastic. These days there are usually grooves under it into which a bedpan may be pushed, presumably in case of emergency or to collect specimens. Alternatively, it can be reversed over the normal lavatory pan and the patient left in peace. I have personally seen these chairs in use within the last three months in the City of York Hospital and the Dorset County Hospital in both medical and surgical wards, and in the Booker Hospital, High Wycombe, geriatric unit, and in the geriatric nursing-home in Hastings run by the Anglican Community of the Nursing Sisters of St. John The Divine. In all these places they are in regular daily use and are a great blessing to patients and staff alike.

\section{Music and Sedation}

Dr. F. J. BenNetr (Colwyn Bay) writes: The idea of inducing sleep by transmitting suitable programmes of music or speech might be tried by the B.B.C. after midnight. I believe that many patients could be helped thereby, and the demand for barbiturates reduced.

\section{Cigarettes in Germany}

Dr. H. G. Caldwell (Whitehead, Co Antrim) writes : I was interested to read in your advertisement columns (September 28 , p. 34) that one of the attractions held out to doctors to join the R.A.M.C. is the low cost of cigarettes in Germany. I wonder if Army medical officers ever engage in health education and if so what line the Army medical directorate advises them to take in instructing young soldiers about smoking and health. 